\title{
Zonisamide Prevents Olanzapine-Associated Hyperphagia, Weight Gain, and Elevated Blood Glucose in Rats
}

\author{
Nicholas M Wallingford ${ }^{1,4}$, Puspha Sinnayah ${ }^{1,4}$, Frank P Bymaster ${ }^{2}$, Kishore M Gadde ${ }^{3}$, Ranga K Krishnan ${ }^{3}$, \\ Anthony A McKinney ${ }^{2}$, Ronald P Landbloom ${ }^{2}$, Gary D Tollefson ${ }^{2}$ and Michael A Cowley*,1,2 \\ 'Division of Neuroscience, Oregon National Primate Research Center, Oregon Health and Science University, Beaverton, OR, USA; ${ }^{2}$ Orexigen \\ Therapeutics Inc., San Diego, CA, USA; ${ }^{3}$ Department of Psychiatry, Duke University, Durham, NC, USA
}

\begin{abstract}
Olanzapine (OLZ), one of the second-generation atypical antipsychotics (SGAs), has shown relative advantages in patient adherence and outcomes. However, OLZ has also been associated with a higher incidence of weight gain than most other SGAs. Excessive weight gain may in turn contribute to long-term health concerns for some individuals. Zonisamide (ZNS), a medication approved in the United States as an adjunct in the management of epilepsy, has a diverse pharmacological profile, including sodium channel blockade, monoamine enhancement, and inhibition of carbonic anhydrase. ZNS has also been reported to cause weight loss in both humans and rodents. We hypothesized that this profile might be beneficial when co-administered with OLZ. To test this hypothesis, we evaluated the effects of OLZ on body weight, as well as the pathways known to regulate feeding behavior and arousal in the Sprague-Dawley rat. As indicated via c-Fos expression, we found an OLZ-induced activation in the nucleus accumbens and orexin neurons in the lateral hypothalamus. An OLZ-associated development of hyperphagia, weight gain and elevated blood glucose in the rat was also found. These outcomes were attenuated and reversed in the presence of concomitant ZNS. These results suggest the hypothesis that ZNS may effectively treat or prevent weight gain or metabolic changes associated with the SGAs. Future studies of this combination in patients through appropriately designed human clinical studies are encouraged.

Neuropsychopharmacology (2008) 33, 2922-2933; doi:I0.1038/npp.2008.9; published online 5 March 2008
\end{abstract}

Keywords: antipsychotic; c-Fos; diabetes; obesity; orexin; therapy

\section{INTRODUCTION}

The second-generation antipsychotics (SGAs), or the socalled 'atypical' antipsychotics, were introduced in an effort to improve on the adverse events associated with the use of the first-generation antipsychotics (FGAs), which often lead to premature drug discontinuation and risk of clinical recurrence. The SGAs have been associated with a lower risk for dopamine (DA) D2 receptor-mediated adverse events such as extra pyramidal symptoms (EPS) (Conley and Kelly, 2005). In turn, where tolerated, patients have reported an improved quality of life (Ritsner and Gibel, 2006).

While relative adherence to treatment has been reported to be better with SGAs as compared with FGAs (Tandon, 2002), as seen in the CATIE study, the majority of schizophrenic patients eventually discontinue treatment

* Correspondence: Dr MA Cowley, Division of Neuroscience, Oregon National Primate Research Center, Oregon Health and Science University, 505 NW 185th Avenue, Beaverton, OR 97006, USA,

Tel: + | 503533 422 I, Fax: + I 5036905384 ,

E-mail: cowleym@ohsu.edu

${ }^{4}$ These authors contributed equally to this work.

Received 7 June 2007; revised 15 January 2008; accepted 17 January 2008 early (Lieberman et al, 2005). In addition, among SGAs, varying degrees of treatment-associated weight gain and related consequences still represent a significant concern (Tarricone et al, 2006). Increased adiposity has been associated with alterations in fasting blood glucose, insulin, low-density lipoprotein levels, and cholesterol (Cooper et al, 2005; Ebenbichler et al, 2003; Henderson et al, 2005; Muoio and Newgard, 2006; Wofford et al, 2006), and a subsequent increased risk for diabetes, morbidity, and mortality (Fontaine et al, 2001; Newcomer, 2005; Strassnig et al, 2003).

Although the phenomenon of weight gain associated with both FGAs and SGAs is well recognized, a precise understanding of the mechanism is not. SGAs such as olanzapine (OLZ) have been found to cause rapid and pronounced hyperphagia in both rodents (Cooper et al, 2005; Cope et al, 2005) and humans (Brixner et al, 2006; Goudie et al, 2005). One hypothetical pathway for this dramatic increase in food consumption may be the activation of orexin neurons in the lateral hypothalamus (LH), and in turn, the release of neuropeptides known to be critical in body weight regulation (Fadel et al, 2002). SGAs, including OLZ, have also been hypothesized to acutely impair glucose metabolism and insulin sensitivity (Brown and Estoup, 
2005; eder-Ischia et al, 2005; Newcomer, 2005). Such adverse events are likely associated with patient noncompliance, place limitations on achieving potential SGA therapeutic advantages, and increase the risk of clinical decompensation and healthcare costs (Newcomer et al, 2004).

This leads to the obvious need for a therapeutic strategy to prevent or treat SGA-associated weight increases. In some of the original studies with zonisamide (ZNS) for epilepsy, weight loss was a reported 'adverse event' (Tosches and Tisdell, 2006). Subsequently, in a randomized controlled trial, Gadde et al (2003) reported that ZNS caused significant weight loss among obese adults. McElroy et al (2006) have also suggested that ZNS might be an effective therapy for binge eating disorder. Given that the female Sprague-Dawley rat has been demonstrated to be an effective model for OLZ-induced weight gain and increased adiposity (Albaugh et al, 2006; Kalinichev et al, 2006; Raskind et al, 2007), we hypothesized that this model could be used to determine the profile of ZNS as a countertherapy for SGA treatment-associated hyperphagia, weight gain, or metabolic events.

\section{MATERIALS AND METHODS}

\section{Subjects}

Female Sprague-Dawley rats (Harlan, Indianapolis, IN) or male C57BL/6J mice (The Jackson Laboratory, Bar Harbor, $\mathrm{ME}$ ) were singly housed under a 12-h light/dark cycle (lights on at $0700 \mathrm{~h})$ and constant temperature $\left(23^{\circ} \mathrm{C}\right)$. Rodents were fed standard chow (Purina Lab Chow no. 5001; $3.34 \mathrm{kcal} / \mathrm{g}$ of energy, $59.8 \%$ carbohydrate, $28 \%$ protein, and $12.1 \%$ fat; Nestle Purina, St Louis, MO), with food and water available ad libitum. All experiments were performed in accordance with the Institutional Animal Care and Use Committee of the Oregon National Primate Research Center, Oregon Health and Science University.

\section{Drugs}

Drug doses were selected on the basis of prior unpublished dose-response studies consistent with other published behavioral and neurochemical studies, in order to minimize detrimental side effects, as well as approximate therapeutic blood levels. Pilot studies also indicated that the effects of OLZ and ZNS (Supplementary Figure S1) on body weight and food intake were dose-dependent, with higher OLZ doses causing sedation. No adverse tissue reactions were found to be associated with any of the drugs administered, and all drug and vehicle solutions were matched to physiological pH (7.35-7.45).

\section{Drug Treatment_-Feeding Studies}

To assess the effects of OLZ on feeding regulation and the impact of ZNS co-administration, female Sprague-Dawley rats were age- and weight-matched (230-275g) and randomly assigned to four treatment groups of 4-6 animals. For osmotic mini-pump (Alzet ${ }^{\circledR}$ 2ML2; Durect Co., Cupertino, CA) infusions, rats were anesthetized using isoflurane and pumps were implanted subcutaneously (SC) between the shoulder blades using sterile surgical procedures. Mini-pumps were used to chronically deliver OLZ in order to minimize stress-related changes in food intake and body weight associated with daily handling and intraperitoneal (IP) injection. Osmotic mini-pumps were preloaded with OLZ (Eli Lilly and Co., Indianapolis, IN) at $1.75 \mathrm{mg} /$ day or control placebo $(1.5 \%$ lactic acid: $100 \mu \mathrm{l}$ of $10 \%$ lactic acid $/ 10 \mathrm{mg}$ of drug) and delivered $5 \mu \mathrm{l}$ per hour for 14 days. Osmotic mini-pumps were primed at $37^{\circ} \mathrm{C}$ in $0.9 \%$ sterile saline for no less than $4 \mathrm{~h}$ prior to implantation. ZNS (Orexigen Therapeutics Inc., San Diego, CA) at $26 \mathrm{mg} /$ $\mathrm{kg}$ or a vehicle solution of $13.4 \% \mathrm{EtOH}, 20.1 \%$ propylene glycol (PPG), and 66.5\% saline (both vehicle and ZNS solution contained dimethylsulfoxide (DMSO) diluted to a final concentration of $10 \%$ ) were injected (IP) two times daily $(0900 / 1700 \mathrm{~h})$ in a volume of $1 \pm 0.2 \mathrm{ml}$ on the basis of body weight. Since ZNS could not be delivered via osmotic mini-pump due to its low solubility, twice-daily injections were necessary to maintain efficacy. Each animal received an osmotic mini-pump, as well as twice-daily injections and comprised the following treatment groups: control + vehicle $(\mathrm{CV}), \mathrm{OLZ}+$ vehicle $(\mathrm{OV})$, control + ZNS (CZ), or OLZ + ZNS (OZ). This experimental protocol was used in two separate experiments. In one experiment, rats were injected twice daily with ZNS, commencing 2 days post-osmotic mini-pump implantation in order to determine whether ZNS treatment could inhibit OLZ-associated hyperphagia and weight gain. In another experiment, rats were injected with ZNS twice daily, commencing 8 days post-osmotic mini-pump implantation in order to determine whether ZNS treatment could reverse OLZ-associated hyperphagia and weight gain. As control for injection-associated stress, rats were sham injected with vehicle 1 week prior to drug treatment injections. Food intake (at the start of the experiment, an equal quantity of food by weight was available to each animal and daily food intake was measured by subtracting the daily weight of the remaining food from the weight of the food from the day prior at the same time each morning) and body weight were recorded daily. Cumulative daily and average daily feed efficiency were calculated as follows: change in body weight $(\mathrm{g}) /$ change in food intake (g). Statistical significance between treatment groups across time was calculated via two-way ANOVA using Bonferroni post tests.

\section{Drug Treatment - Blood Glucose}

We studied potential acute changes in glucose related to OLZ-associated weight gain, as well as the impact of ZNS co-therapy on glucose homeostasis. Blood glucose was measured in female Sprague-Dawley rats (4-6 animals per treatment group on day 13 of chronic OLZ treatment $/ 2 \mathrm{~h}$ after the $0900-\mathrm{h}$ ZNS injection on day 5 of subchronic ZNS treatment of the hyperphagia and weight gain reversal experiment) via saphenous vein bleeds.

Our laboratory has extensive experience and expertise in using a male mouse model for acute glycemic control studies (Enriori et al, 2007). We further tested the acute effects of ZNS on blood glucose using male C57BL/6J mice ( 5 animals per treatment group $2 \mathrm{~h}$ post drug treatment) via saphenous vein bleeds in order to investigate the mechanism of the effect of ZNS treatment on OLZ-associated glucose dysregulation and to determine to what extent 
increased blood glucose was weight-related. Mice received either OLZ (1.5, 5 or $10 \mathrm{mg} / \mathrm{kg}$ ), ZNS (26 and $75 \mathrm{mg} / \mathrm{kg}$ ), OLZ $(10 \mathrm{mg} / \mathrm{kg})+\mathrm{ZNS}(26 \mathrm{mg} / \mathrm{kg})$, or the vehicle in a volume of $0.1 \pm 0.02 \mathrm{ml}$ on the basis of body weight. Blood was collected (approximately $10 \mu \mathrm{l}$ ) using heparinized capillary tubes (15401-628; VWR International, West Chester, PA), applied to test strips (03145263001; AccuChek ${ }^{\circledR}$ Advantage; Roche, Basel, Switzerland), and analyzed using a glucometer (Accu-Chek Advantage, 860; Roche).

\section{Drug Treatment - Immunohistochemical Studies}

To determine the cell types and brain regions putatively involved in OLZ-associated hyperphagia and weight gain, as well as the homeostatic effects of ZNS co-therapy, female Sprague-Dawley rats were age- and weight-matched (280$310 \mathrm{~g}$ ) and randomly assigned to four treatment groups of 3-4 animals. Each animal was injected SC with one of the following: vehicle (13.4\% $\mathrm{EtOH}, 20.1 \% \mathrm{PPG}, 66.5 \%$ saline), OLZ (10 mg/kg), ZNS (30 mg/kg), or OLZ + ZNS in a volume of $1 \pm 0.2 \mathrm{ml}$ based on body weight (Robertson and Fibiger, 1996). Drugs and vehicle were dissolved in a mixture of $1.5 \%$ lactic acid ( $100 \mu \mathrm{l}$ of $10 \%$ lactic acid/10 mg of drug) for OLZ and in $10 \%$ DMSO for ZNS. Two hours post-injection, all animals were anesthetized with pentobarbital $(50 \mathrm{mg} / \mathrm{ml}$ IP) and perfused with saline $(300 \mathrm{ml})$, followed by treatment with $500 \mathrm{ml}$ of fresh, cold $4 \%$ paraformaldehyde dissolved in $0.1 \mathrm{M}$ sodium phosphate-buffered saline at $\mathrm{pH}$ 7.4. Each rat brain was removed immediately after perfusion and postfixed in $4 \%$ paraformaldehyde overnight $(20 \mathrm{~h})$. Brains were then washed in potassium phosphate-buffered saline (KPBS) $(0.05 \mathrm{M})$ and stored in a solution of $25 \%$ sucrose.

\section{Immunohistochemistry}

Prior to sectioning, each brain was flash frozen in isopentane and stored at $-80^{\circ} \mathrm{C}$. Each brain was cut using a microtome caudally to rostrally into $30-\mu \mathrm{m}$ serial coronal sections ( 1 in 6 ) and cryoprotected in a 33\% ethylene glycol, $33 \%$ sucrose, $0.05 \mathrm{M}$ sodium phosphate solution. Sections were washed in KPBS and incubated in $1 \%$ hydrogen peroxide for $10 \mathrm{~min}$ in order to block endogenous peroxidase activity. To assess putative neuronal involvement of OLZ-associated weight gain, neurons known to be associated with feeding behavior (orexin and $\mathrm{MCH}$ ) were examined for c-Fos activity. Sections were incubated with a rabbit polyclonal antibody (sc-52, 1:20000; Santa Cruz Biotechnology, Santa Cruz, CA) directed against the $\mathrm{N}$-terminus of the human c-Fos molecule, a goat polyclonal antibody (sc-8070, 1:5000; Santa Cruz Biotechnology) directed against the C-terminus of the human orexin-A peptide, and a chicken polyclonal antibody (T-1506, 1:3000; Bachem, Heidelberg, Germany) directed against the fulllength 18-residue human melanin-concentrating hormone peptide. Fos immunohistochemistry was performed using the Nickel-DAB method described by Sebens et al (1995). Fluorescent immunohistochemistry was performed by incubating the sections in fluorescein isothiocyanate (FITC)-conjugated donkey anti-goat and rhodamine (TRITC)-conjugated donkey anti-chicken fluorescent secondary antibodies (705-095-003, 703-025-155, 1:200; Jackson ImmunoResearch) in KPBS for $2 \mathrm{~h}$. The sections were then washed in KPBS and mounted on precleaned slides subbed in a $0.2 \%$ gelatin $/ 0.02 \%$ chromic potassium sulfate solution. The slides were then coverslipped using Fluoromount-G (0100-01; Southern Biotech, Birmingham, AL).

\section{c-Fos-Positive Cell Counts, Fluorescent Cell Counts, and Double Labeling}

c-Fos expression was determined by light microscopy (Nikon Eclipse E800 Series; Nikon, Melville, NY). Digital image capture (CoolSnapHQ camera system; Photometrics, Tuscon, AZ, using Metamorph software; Molecular Devices Corp., Sunnyvale, CA) allowed the analysis of c-Fos-positive cells by manual counting. Bilateral digital images at $\times 10$ magnification were fitted with a grid using Adobe Photoshop and blind to treatment group, manual cell counts of c-Fos positive cells (appearing round or oval and stained intensely black) were performed for each region of interest within a standardized area for each rat brain (Robertson and Fibiger, 1996). For each sample of the same anatomical region of interest, the grid was placed with respect to local landmarks and with effort to place the grid consistently for all samples. There was some variance in the dimensions of each grid $(1000-1500 \times 1000-1500 \mu \mathrm{m})$ as each region of interest differed in size and shape. Values are shown as the average number of c-Fos-positive cells per brain section for each region analyzed. The brain regions analyzed (identified using the rat brain atlas of Swanson, 1998) were the nucleus accumbens core (NAcC) and shell (NAcSh) and the LH, due to significant activity observed in these regions. A total of 4-8 anatomically matched sections per brain were analyzed for each treatment group. The number of single (orexin or $\mathrm{MCH}$ ) or double labeled (orexin/c-Fos or MCH/c-Fos) cells was found by examining six levels of the hypothalamus per rat brain using a combination of fluorescent and light microscopy. Values are shown as the percentage of orexin neurons expressing c-Fos. Statistical significance between treatment groups was calculated by a two-way ANOVA using Bonferroni post tests.

\section{RESULTS}

\section{ZNS Inhibits OLZ-Associated Hyperphagia, Weight Gain, and Increased Feed Efficiency}

Rats treated chronically (2 weeks) with OLZ alone (OV, $1.75 \mathrm{mg} /$ day) gained significantly more weight than the control animals (CV) on days 8 and 12, and consumed significantly more chow on days 5-12 of osmotic minipump infusion. Rats receiving $\mathrm{OV}$ treatment also gained significantly more weight than rats treated with OLZ and ZNS (OZ) on days $8,10-12$, and consumed significantly more chow on days $6-12$ of osmotic mini-pump infusion (Figure 1a and b). (The shaded area is the time of drug infusion, which is followed by a drug washout period.) In addition, OLZ (OV)-treated animals continued to eat significantly more chow than $\mathrm{CV}$ - and OZ-treated animals on days 13 and 14 following the end of the time of drug infusion (Figure 1b). OLZ treatment alone also significantly increased feed efficiency (change in body weight (g)/change in food intake $(\mathrm{g})$ ) on days 6-12 of osmotic mini-pump infusion compared with $\mathrm{CV}$ and on day 7 compared with 
a
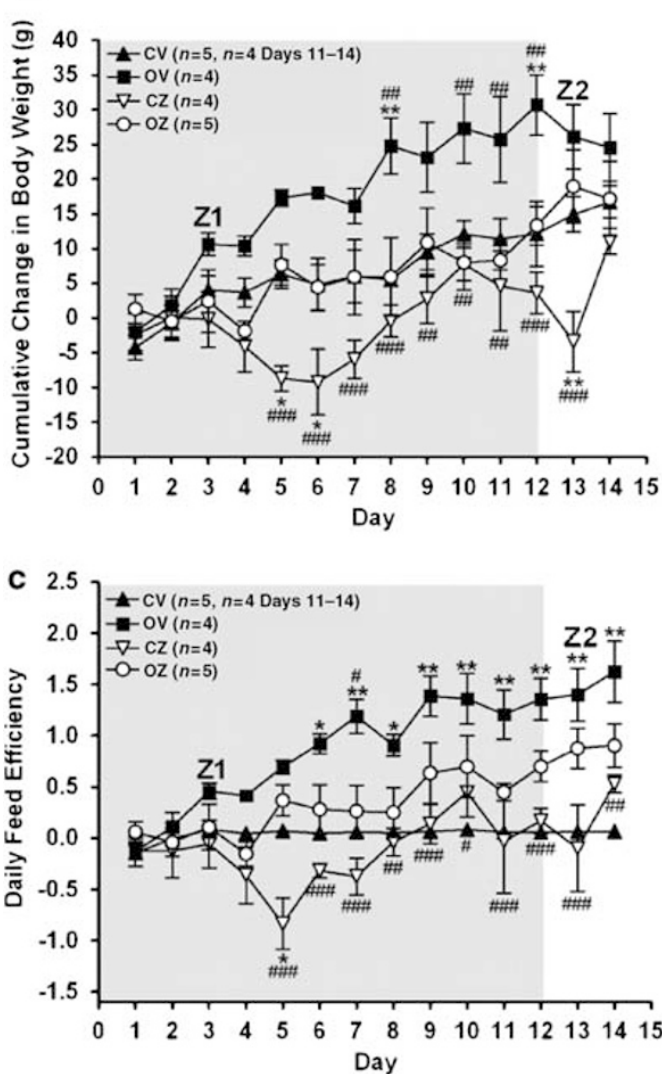

b
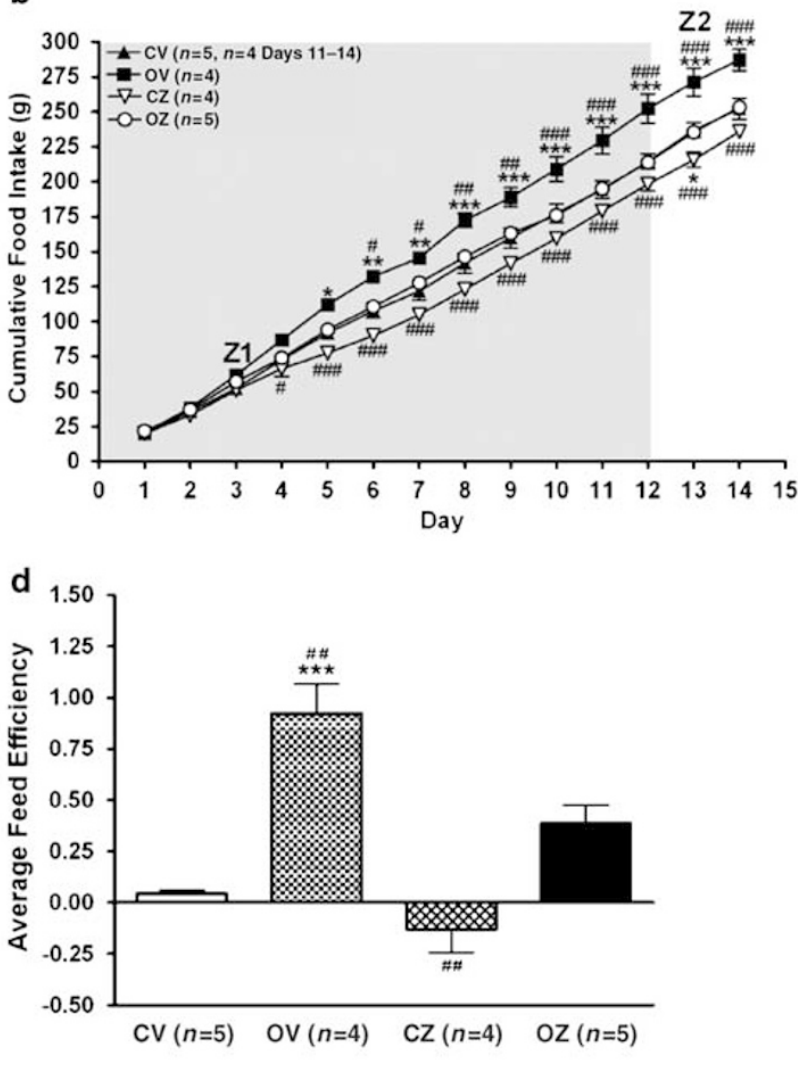

Figure I ZNS inhibits OLZ-associated weight gain, hyperphagia, and increased feed efficiency. Female Sprague-Dawley rats were implanted with osmotic mini-pumps containing a placebo control (CV) or olanzapine (OLZ) at $1.75 \mathrm{mg} /$ day $(\mathrm{OV})$, followed 2 days later by twice-daily injections with ZNS at $26 \mathrm{mg} /$ $\mathrm{kg}(\mathrm{OZ})$ or vehicle (CZ). Food intake and body weight were measured daily. ZNS inhibited OLZ-associated weight gain (a), food intake (b), daily feed efficiency (change in body weight (g)/change in food intake (g)) (c), and average feed efficiency (d). The shaded area is the time of drug infusion, which is followed by a drug washout period. ${ }^{*} p<0.05$, ${ }^{*} * p<0.01$, ${ }^{*} * * * p<0.001$ compared with the vehicle; ${ }^{\#} p<0.05,{ }^{\# \#} p<0.0$ I, ${ }^{\# \#} p<0.00$ I compared with OLZ + ZON (OZ). ZI = start of ZNS injections $(26 \mathrm{mg} / \mathrm{kg}, 0900 / 1700 \mathrm{~h}) ; Z 2=$ end of ZNS injections.

OZ. This increased feed efficiency was also seen on days 13 and 14 following the end of the time of drug infusion compared with CV (Figure 1c). OLZ (OV) also induced a 23 -fold increase in average feed efficiency $(0.92 \pm 0.04 v s$ $0.04 \pm 0.02$ ) over CV-treated animals, and a 2.5 -fold increase in average feed efficiency $(0.92 \pm 0.04$ vs $0.39 \pm 0.18)$ over OZ-treated animals during the entire course of drug treatment (Figure 1d). In contrast, animals treated with ZNS alone (CZ, $26 \mathrm{mg} / \mathrm{kg}$ twice daily) lost a significant amount of weight $v s \mathrm{CV}$ on days 5, 6, and 13, and showed a trend toward decreased food consumption on days 5-12 and 14, and consumed significantly less chow on day 13 (Figure 1a and b). ZNS treatment alone also significantly decreased feed efficiency on day 5 of osmotic mini-pump infusion (Figure 1c) and induced a threefold decrease in average feed efficiency $(-0.08 \pm 0.04 v s 0.04 \pm 0.02)$ from $C V$ (Figure 1d). There were no significant differences in body weight, food intake, or feed efficiency between the CV-treated animals and the animals administered ZNS in addition to OLZ infusion (OZ) on any treatment day (Figure 1a-d). Thus, not only did ZNS administration induce weight loss in vehicle treated animals, it also inhibited chronic OLZ-associated hyperphagia, weight gain, and increased feed efficiency in OLZ-treated animals.

\section{ZNS Reverses OLZ-Associated Hyperphagia, Weight Gain, and Increased Feed Efficiency}

Rats administered ZNS over 7 days following subchronic (8 days) osmotic mini-pump infusion of control (CV) weighed significantly less on day 12 and consumed significantly less chow on days 12-16 than CV animals (Figure 2a and b). ZNS also induced a trend toward a decrease in feed efficiency on day 12 of osmotic mini-pump infusion and a decrease in average feed efficiency $v s \mathrm{CV}$ $(-0.05 \pm 0.02$ vs $0.41 \pm 0.04)$ (days $9-15$ of ZNS treatment) (Figure $2 c$ and $d$ ). Rats treated with OLZ (OV) gained significantly more weight on days 11-13 and consumed significantly more chow than CV animals on days $10-14$ of osmotic mini-pump infusion. Rats treated with OLZ (OV) also gained significantly more weight and consumed significantly more chow on days 13 and 14 compared with $\mathrm{OZ}$ animals (Figure 2a and b). Additionally, OLZ (OV)treated animals continued to eat significantly more chow than CV-treated animals on days 15 and 16 (and on day 15 compared with $\mathrm{OZ}$ ) following the end of the time of drug infusion (Figure 2b). OLZ treatment also induced a trend toward an increase in feed efficiency compared with $\mathrm{CV}$ and $\mathrm{OZ}$ on days 11-14 of osmotic mini-pump infusion, as well as on day 15 after the time of drug infusion (Figure 2c). 
a
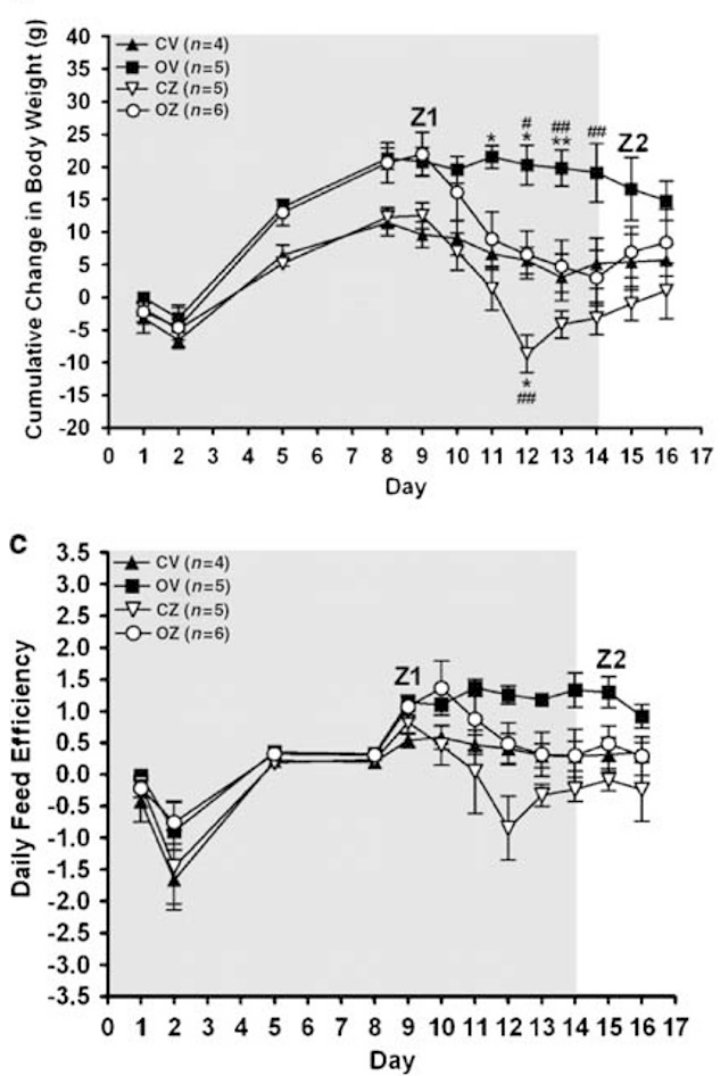

b
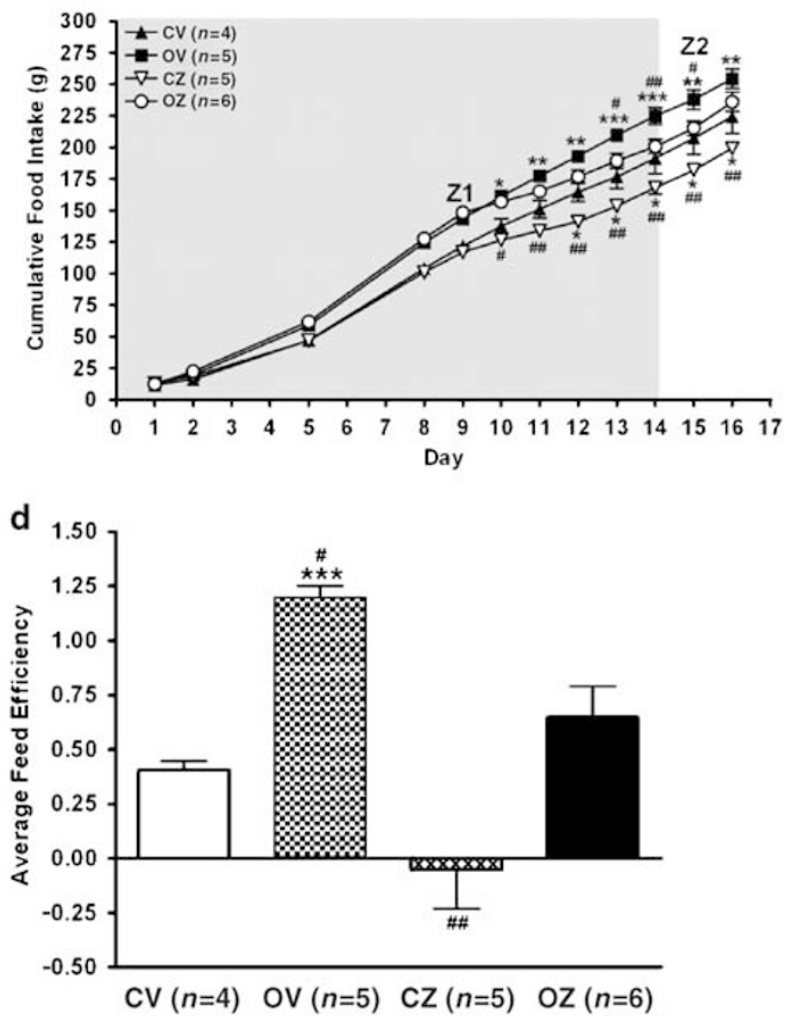

Figure 2 ZNS reverses OLZ-associated weight gain, hyperphagia, and increased feed efficiency. Female Sprague-Dawley rats were implanted with osmotic mini-pumps containing a placebo control (CV) or OLZ at $1.75 \mathrm{mg} /$ day (OV), followed 8 days later by twice-daily injections with ZNS at $26 \mathrm{mg} / \mathrm{kg}$ $(\mathrm{OV})$ or vehicle (CV). Food intake and body weight were measured daily. ZNS reversed OLZ-associated weight gain (a), food intake (b), daily feed efficiency (change in body weight $(\mathrm{g}) /$ change in food intake $(\mathrm{g})$ ) (c), and average feed efficiency (days 9-15 of ZNS treatment) (d). The shaded area is the time of drug infusion, which is followed by a drug washout period. ${ }^{*} p<0.05$, ** $p<0.0$ I, **** $p<0.00$ I compared with the vehicle; ${ }^{*} p<0.05$, $\# \# p<0.0$ I compared with $\mathrm{OLZ}+\mathrm{ZON}(\mathrm{OZ}) \cdot \mathrm{ZI}=$ start of ZNS injections $(26 \mathrm{mg} / \mathrm{kg}, 0900 / \mathrm{I} 700 \mathrm{~h}) ; \mathrm{Z2}=$ end of ZNS injections.

OV-treated animals also showed a threefold increase in average feed efficiency compared with CV-treated animals $(1.20 \pm 0.05$ vs $0.41 \pm 0.04)$ and a twofold increase compared with OZ-treated animals $(1.20 \pm 0.05$ vs $0.65 \pm 0.32)$ (Figure 2d). There were no significant differences in body weight, food intake, or feed efficiency between the animals administered ZNS (7 days) following OLZ and the CVtreated animals (Figure $2 \mathrm{a}-\mathrm{d}$ ). Therefore, treatment with ZNS reversed chronic OLZ-associated hyperphagia, weight gain and increased feed efficiency.

\section{ZNS Reversed Acute OLZ-Associated Changes in Blood Glucose}

Rats treated chronically with OLZ alone had significantly elevated blood glucose $(127 \pm 4.5 \mathrm{mg} / \mathrm{dl})$ compared with vehicle-treated control animals $(94.3 \pm 7.1 \mathrm{mg} / \mathrm{dl})$, animals receiving co-administration of OLZ and ZNS for 5 days $(97.7 \pm 2.3 \mathrm{mg} / \mathrm{dl})$, and animals treated with ZNS alone $(109.2 \pm 3.9 \mathrm{mg} / \mathrm{dl})$. Rats treated chronically with ZNS alone and those receiving co-administration of OLZ and ZNS for 5 days did not have blood glucose levels significantly different from those in CV-treated animals (Figure 3a). Thus, ZNS treatment lowered OLZ-associated elevated blood glucose in OZ-treated rats.
Mice treated with OLZ had significant increase in their non-fasting blood glucose levels $2 \mathrm{~h}$ after drug treatment at doses of $5 \mathrm{mg} / \mathrm{kg} \quad(219.4 \pm 12.1 \mathrm{mg} / \mathrm{dl})$ and $10 \mathrm{mg} / \mathrm{kg}$ $(237.4 \pm 12.8 \mathrm{mg} / \mathrm{dl})$, compared with vehicle-treated animals $(131.4 \pm 6.8 \mathrm{mg} / \mathrm{dl}$ ) (Figure $3 \mathrm{~b})$. There were no significant differences in non-fasting blood glucose between mice treated with 26 and $75 \mathrm{mg} / \mathrm{kg}$ of ZNS $(139.2 \pm 6.2 /$ $144 \pm 5.3 \mathrm{mg} / \mathrm{dl}$, respectively) compared with vehicle controls $(132 \pm 9 \mathrm{mg} / \mathrm{dl}$ ) (Figure $3 \mathrm{c}$ ). In another experiment, mice treated acutely with OLZ $(10 \mathrm{mg} / \mathrm{kg}: 305 \pm 10.6 \mathrm{mg} / \mathrm{dl})$ or OLZ + ZNS (10 mg/kg + 26 mg/kg: $296.7 \pm 13.6 \mathrm{mg} / \mathrm{dl})$ had significantly elevated non-fasting blood glucose $2 \mathrm{~h}$ after drug treatment compared with vehicle-treated animals $(131.3 \pm 4.2 \mathrm{mg} / \mathrm{dl})$. There were no significant differences in non-fasting glucose levels between mice treated acutely with ZNS $(26 \mathrm{mg} / \mathrm{kg}: 109.7 \pm 11.6)$ and vehicle-treated animals, and between mice treated acutely with OLZ and $\mathrm{OLZ}+\mathrm{ZNS}$-treated animals (Figure 3d). The OLZ-associated acute increase in non-fasting blood glucose indicates that OLZ treatment alone can be a weight-independent factor in glucose dysregulation. Although acute ZNS treatment had no significant effect on acute OLZ-associated elevated blood glucose in mice, subchronic ZNS treatment resulted in the significant reduction of OLZ-associated elevated blood glucose in rats. 

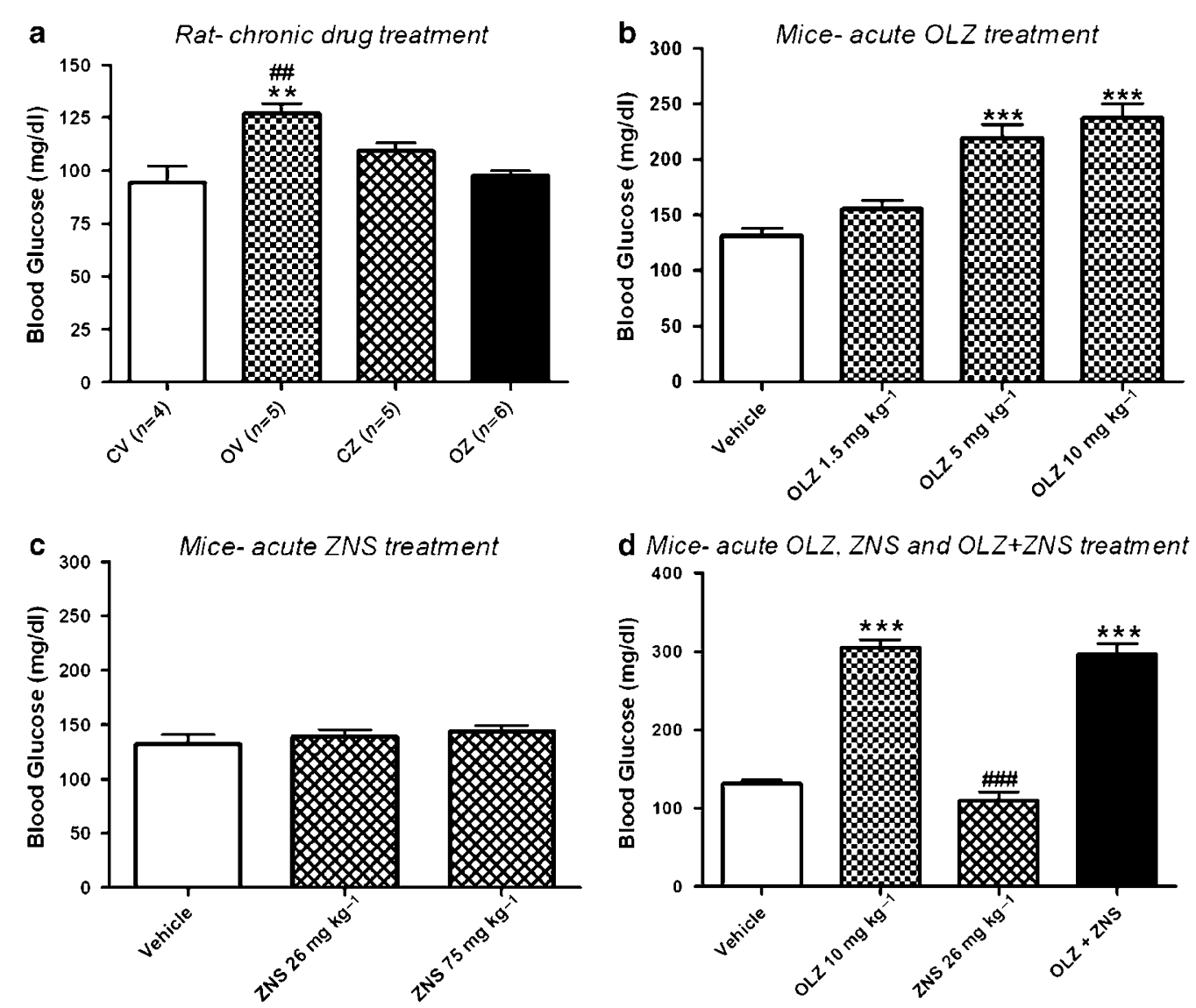

Figure 3 ZNS lowers OLZ-associated elevated blood glucose. Blood glucose was measured in female Sprague-Dawley rats 13 days post osmotic minipump implantation, $2 \mathrm{~h}$ after the 0900-h ZNS injection on day 5 of subchronic ZNS treatment of the weight gain and hyperphagia reversal experiment, and in C57BL/6J mice $2 \mathrm{~h}$ post OLZ, ZNS, or OLZ + ZNS treatment. (a) OV chronically treated rats had significantly elevated blood glucose levels compared with CV-treated rats. Although chronic ZNS treatment alone (CZ) increased blood glucose compared with control levels, subchronic ZNS treatment significantly lowered blood glucose levels in rats chronically treated with olanzapine $(O Z)$ back to baseline levels. *** $<0.01$ compared with the vehicle; $\# p<0.01$ compared with OLZ +ZON (OZ). (b) Acute OLZ at 5 and $10 \mathrm{mg} / \mathrm{kg}$ significantly increased baseline blood glucose in mice ( $n=5$, **** $p<0.00$ I compared with the vehicle). (c) Acute ZNS at 26 and $75 \mathrm{mg} / \mathrm{kg}$ had no effect on baseline blood glucose in mice ( $n=5)$. (d) Acute OLZ $(10 \mathrm{mg} / \mathrm{kg})$ and OLZ + ZNS (10 mg/kg $+26 \mathrm{mg} / \mathrm{kg})$-treated mice had significantly elevated blood glucose levels compared with vehicle-treated mice, while there were no significant differences in blood glucose levels between mice treated acutely with ZNS alone $(26 \mathrm{mg} / \mathrm{kg})$ and vehicle-treated mice $\left(* * * * 0.001\right.$ compared with the vehicle; ${ }^{\# \#} p<0.00$ I compared with OLZ + ZON).

\section{ZNS Attenuates OLZ-Associated Activation of Neurons in the Nucleus Accumbens and LH of the Rat Brain}

Acute administration of OLZ (10 mg/kg), ZNS $(30 \mathrm{mg} / \mathrm{kg})$, and $\mathrm{OLZ}+\mathrm{ZNS}$ produced significant increase in the activation of cells (c-Fos-positive cells per section) compared with vehicle in the rat $\mathrm{NAcC}, \mathrm{NAcSH}$, and $\mathrm{LH}$ (Table 1; Figure 4). OLZ was associated with a significantly greater increase in c-Fos-positive cells when compared with ZNS alone in the NACC and LH (Table 1; Figure 4). ZNS treatment produced significant attenuation of OLZ-associated cell activation in the $\mathrm{NAcC}$ and $\mathrm{NAcSH}$, whereas a trend toward ZNS reduction in cell activation was observed in the LH (Table 1; Figure 4).

\section{ZNS Attenuates OLZ-Associated Orexin Neuron Activation}

Double labeling in rat brain via immunohistochemistry showed that acute OLZ treatment $(\mathrm{OV}, 10 \mathrm{mg} / \mathrm{kg}$ ) significantly increased the percentage of orexin neurons expressing c-Fos $(38.7 \pm 2 \%)$ compared with CV-treated animals
$(0.4 \pm 0.2 \%)$ in the LH. Although ZNS treatment $(30 \mathrm{mg} / \mathrm{kg})$ also increased the percentage of c-Fos-positive orexin neurons $(15.5 \pm 1.3 \%)$ compared with the control animals, the increase associated with OLZ treatment alone was attenuated by co-administration with ZNS $(18.9 \pm 2 \%)$ (Figure 5; Table 2). Fluorescent immunohistochemistry showed $\mathrm{MCH}$ neurons as a separate neuronal population from orexin neurons and there were no instances of orexin $+/ \mathrm{MCH}+$ cells (Figure 6). All drug treatments resulted in negligible activation of $\mathrm{MCH}$ neurons and the number of orexin and $\mathrm{MCH}$ labeled neurons was not significantly different between treatment groups (Table 2). Although both orexin and $\mathrm{MCH}$ neurons are associated with the induction of food consumption, it appears that the mechanism of OLZ-associated weight gain is $\mathrm{MCH}$ neuron independent.

\section{DISCUSSION}

The SGAs are effective antipsychotic agents; however, in some individuals, associated weight gain and related 
Table I Fos-Like Immunoreactivity in the Nucleus Accumbens and LH of the Rat Brain Feeding Circuit Regions of the Brain

\begin{tabular}{|c|c|c|c|c|}
\hline & Vehicle & Olanzapine & Zonisamide & Olanzapine+zonisamide \\
\hline $\mathrm{NAcC}$ & $18.1 \pm 4.8$ & $317.3 \pm 9.1$ ****,\#\#\# & $178.6 \pm 16.0 *$ **** & $132.9 \pm 7.2 * * * *$ \\
\hline NAcSh & $15.3 \pm 4.7$ & $233.3 \pm 5.9$ ****,\#\#\# & $226.5 \pm 4.3 *$ ***.\#\#\# & $139.3 \pm 21.3 * * * *$ \\
\hline $\mathrm{LH}$ & $13.0 \pm 3.9$ & $212.0 \pm 21.5 * * *$ & $138.7 \pm \mid 4.2$ ****** & $177.3 \pm 25.4$ ***** \\
\hline
\end{tabular}

Abbreviations: $\mathrm{LH}=$ lateral hypothalamus; $\mathrm{NAcC}=$ nucleus accumbens core; NAcSh = nucleus accumbens shell.

Data are expressed as mean \pm SEM; $* * * *<0.001$ from the vehicle, and ${ }^{\# \# \# ~} p<0.00$ I from olanzapine+zonisamide by two-way ANOVA.

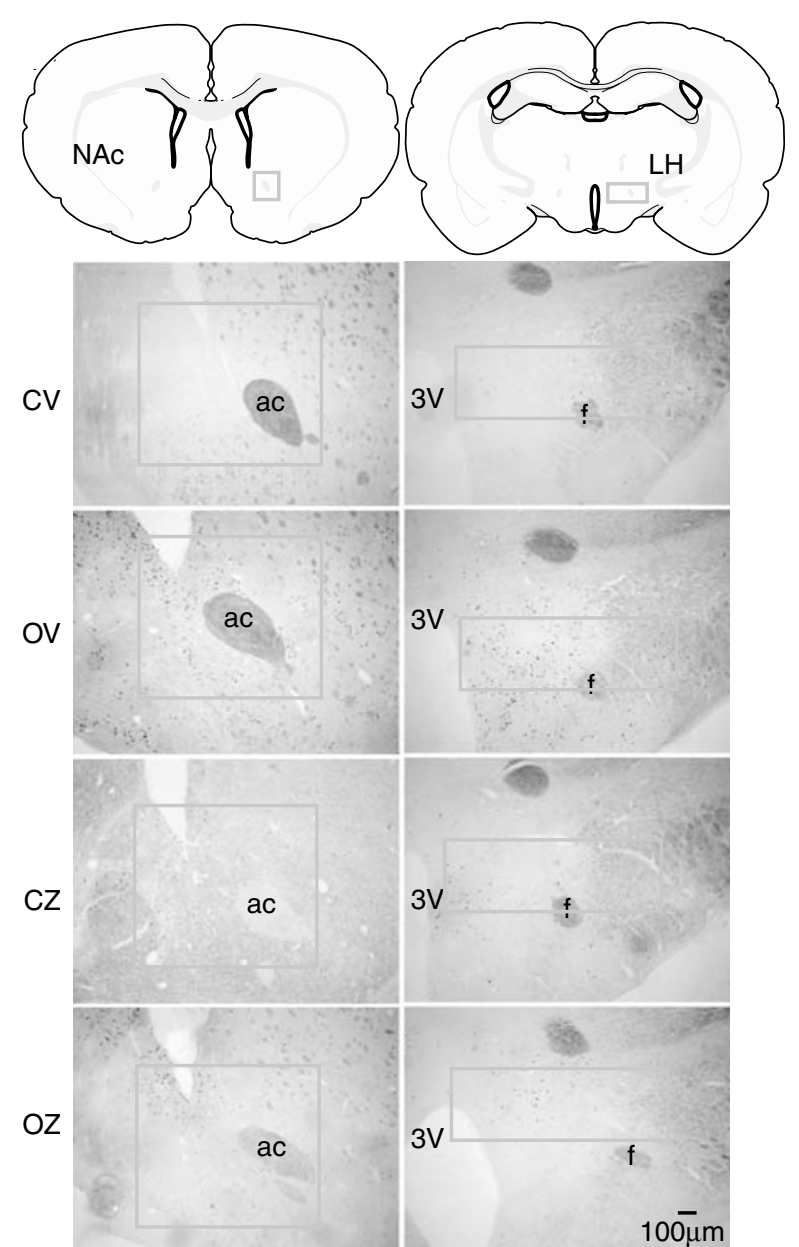

Figure 4 Representative photomicrographs showing c-Fos immunoreactivity in the $\mathrm{NAcC}$ and the $\mathrm{LH}$ in response to subcutaneous vehicle (CV), OLZ (OV) $(10 \mathrm{mg} / \mathrm{kg})$, zonisamide (CZ) $(30 \mathrm{mg} / \mathrm{kg})$, or OLZ + ZNS (OZ) treatment. ZNS attenuates OLZ-associated increases in c-Fos expression. There is decreased expression of c-Fos in OZ-treated animals compared with OV-treated animals in the NAcC and $\mathrm{LH}$. The gray box outlines the regions where cells were counted. Images were captured at $\times 4$ magnification. Scale bar, $100 \mu \mathrm{m}$. ac, anterior commissure; 3V, third ventricle; $f$, fornix.

metabolic consequences may limit their potential utility. One method to identify a clinical approach toward a weight management strategy is to better understand how SGAs might affect CNS feeding circuitry. Antipsychotic drugassociated weight gain in a male rodent model has been shown by Minet-Ringuet et al (2006); however, clozapine has not been found to induce weight gain or metabolic abnormalities in female rats, but was found to increase

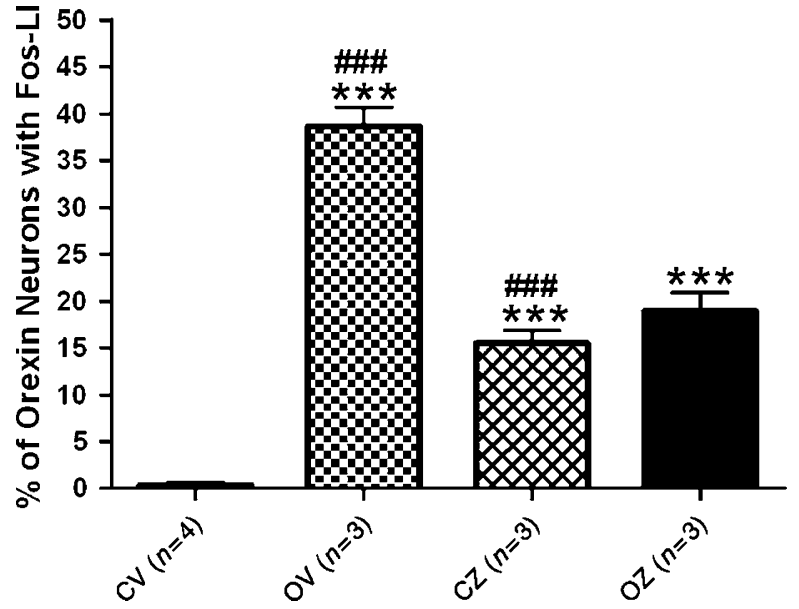

Figure 5 ZNS attenuates $\mathrm{OLZ}$-associated orexin neuron activation. Female Sprague-Dawley rats were killed $2 \mathrm{~h}$ post subcutaneous injection with OLZ ( $10 \mathrm{mg} / \mathrm{kg})$, ZNS $(30 \mathrm{mg} / \mathrm{kg})$, OLZ + ZNS, or vehicle. Following perfusion, rat brains were removed, sectioned, and stained with anti-c-Fos and anti-orexin antibodies, and manual counts of positively immunoassayed neurons were made. OLZ treatment associated c-Fos expression in a significantly higher percentage of orexin neurons compared with vehicle treatment. ZNS treatment alone also increased c-Fos activation in orexin neurons, but co-administration attenuated $\mathrm{OLZ}$-associated c-Fos activation ${ }^{* * * *} p<0.001$ compared with the vehicle; ${ }^{\# \#} p<0.00$ I compared with OLZ+ ZON (OZ))

adiposity (Cooper et al, 2007). Although antipsychotic drugassociated weight gain in rodent models is in dispute in regard to sex, drug administration, diet, dose, and antipsychotic agents used, the use of OLZ in female rats has consistently been demonstrated to reproduce the weight gain, increased adiposity, and metabolic disturbances seen in patients (Albaugh et al, 2006; Arjona et al, 2004; Coccurello et al, 2006; Cooper et al, 2005; Cope et al, 2005; Goudie et al, 2002; Raskind et al, 2007). With a similar rodent model, we have shown that ZNS both inhibits and reverses SGA-associated hyperphagia, weight gain, and increased feed efficiency. In addition, ZNS attenuates both OLZ-associated elevated blood glucose, as well as OLZassociated activation of feeding-circuit neurons.

The orexin neurons in the lateral hypothalamic/perifornical area (LH/PFA) express neuropeptides that are potent regulators of body weight, mood, arousal, and reward (Harris et al, 2005; Preti, 2002; Sakurai, 2003). Orexin axons are distributed throughout the brain, and may regulate melanocortin circuits, which coexpress the orexigenic peptides neuropeptide $\mathrm{Y}$ and agouti-related protein associated with increased food consumption (Elman et al, 2006; Kalra and Kalra, 2004; Schwartz and Porte, 2005). Fadel et al 
Table 2 Fos-Like Immunoreactivity in Orexin and MCH Neurons

\begin{tabular}{lcccc}
\hline & Vehicle & Olanzapine & Zonisamide & Olanzapine+zonisamide \\
\hline Percentage of MCH neurons expressing c-Fos & $0.005 \pm 0.0006$ & $0.005 \pm 0.0007$ & $0.006 \pm 0.0004$ & $0.005 \pm 0.0005$ \\
Percentage of orexin neurons expressing c-Fos & $0.4 \pm 0.2$ & $38.7 \pm 2.0 * * * * \# \# \#$ & $15.5 \pm 1.3 * * * * \# \# \#$ & $18.9 \pm 2.0$ \\
Orexin cells per section & $124.4 \pm 8.5$ & $132.3 \pm 9.0$ & $136.4 \pm 13.3$ & $133.2 \pm 5.6$ \\
$M C H$ cells per section & $413.2 \pm 9.3$ & $431 \pm 6.8$ & $421.1 \pm 12.7$ & $4 \mid 2.8 \pm 11.5$ \\
\hline
\end{tabular}

Data are expressed as mean \pm SEM; **** $p<0.00$ I from the vehicle, and ${ }^{\# \# \#} p<0.00$ I from olanzapine+zonisamide by two-way ANOVA.



b $\quad \mathrm{MCH}$
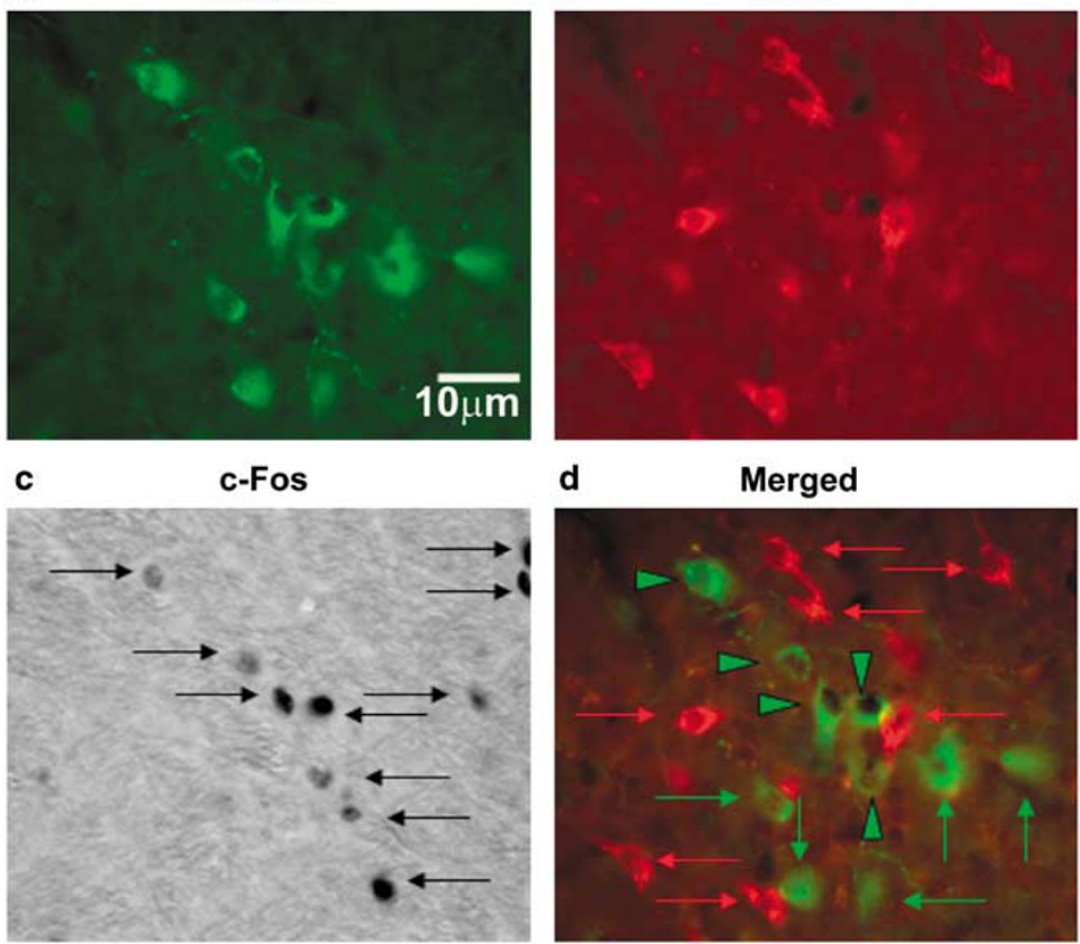

d

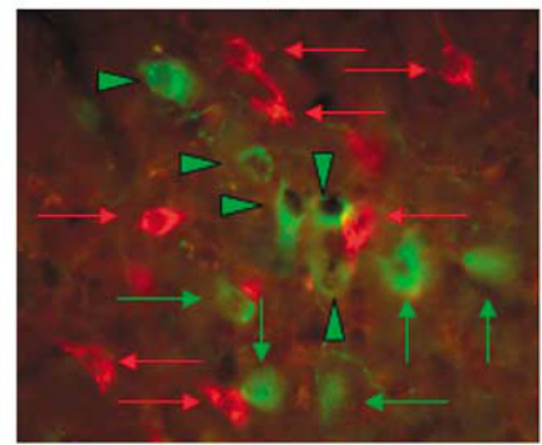

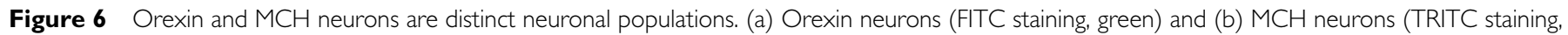

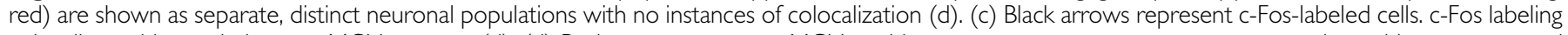

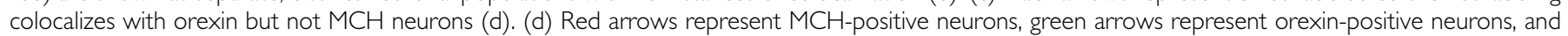
green arrowheads represent c-Fos- and orexin-positive neurons. Images were captured at $\times 40$ magnification. Scale bar, I0 $\mu$ m.

found via Fos-like immunoreactivity (Fos-LI) that of the four SGAs associated with the greatest post-treatment weight gain, OLZ activated the highest density of cells in the medial LH/PF. In addition, OLZ activated $20-30 \%$ of orexin neurons found in the medial LH/PF (Fadel et al, 2002). In contrast, $\mathrm{MCH}$ neurons of the $\mathrm{LH}$, which are also associated with the induction of food consumption, were unaffected. Consistent with these findings, we found that OLZ induced the activation of $38 \%$ of the orexin neurons of the LH/PFA in rat brain, whereas a negligible amount of Fos-LI was seen in $\mathrm{MCH}$ neurons. This suggests a heterogeneity between these two groups of orexigenic neurons in regard to their neural connectivity and roles in the regulation of behavioral state (Cvetkovic et al, 2004; Modirrousta et al, 2005).

Although the exact mechanism of OLZ-associated weight gain is unknown, OLZ may be better characterized by the analysis of Fos-LI in nuclei receiving projections from orexin neurons with connections to feeding-circuit regions and reward pathways of the rat brain (Harris and AstonJones, 2006). The orexin neurons are also known to project to key structures of the limbic system, and orexin receptors, both orexin receptor type 1 and type 2, are expressed in the $\mathrm{NAcC}$ and NAcSH (Cluderay et al, 2002; Hervieu et al, 2001). Via Fos labeling, we found that OLZ induced a significantly larger degree of cell activation compared to vehicle in the nucleus accumbens (NAcC and NAcSh) and the LH. The significant increases in Fos-LI that we report are consistent with the findings of others (Ward et al, 2006; Will et al, 2003). These increases in Fos-LI may imply a connection between the orexigenic systems involved not only in food intake, but also with reward-associated food preferences, including consumption of high-fat, palatable foods (Harris et al, 2005; Kelley et al, 2005; Preti, 2002; Sakurai, 2003). In view of these results, we speculate that therapies aimed at mitigating OLZ-associated hyperphagia 
and weight gain may have targets in the orexin-regulated feeding networks of the central nervous system (Baptista et al, 2002; Elman et al, 2006).

Although the exact antiepileptic mechanism of ZNS has yet to be identified, it is known to enhance neuronal inhibition via modulation of several neurotransmitter systems. Antiepileptics have also been shown to potentiate both typical and atypical antipsychotic-induced prefrontal cortical dopamine release in the rat (Ichikawa et al, 2005) by $5-\mathrm{HT}_{1 \mathrm{~A}}$ receptor activation (Ichikawa and Meltzer, 1999). $\mathrm{D}_{2}$ receptor agonists are known to inhibit feeding in rats (Kuo, 2002; Terry et al, 1995); therefore, it is also possible that the anorectic properties of ZNS may relate to the augmentation of dopamine synthesis and/or stimulation of $\mathrm{D}_{2}$ receptors (Okada et al, 1995). The antiepileptic activity of ZNS may be mediated by a decreased production of GABA transporters, resulting in increased tissue and synaptic concentrations of GABA and enhanced GABA mediated neuronal inhibition (Czapinski et al, 2005). ZNS is also thought to potentially inhibit glutamate mediated neuronal excitation (Maldonado-Irizarry et al, 1995). This may explain our finding that ZNS attenuated the degree of OLZ-associated Fos-LI in the nucleus accumbens. Maldonado-Irizarry and co-workers also found that glutamate receptors in the NAcSh are involved in the control of feeding behavior via the LH. Moreover, both dopamine and GABA play a modulatory role in the regulation of this feeding response (Stratford and Kelley, 1997). In addition, GABA in the NAcSh has been shown to participate in the central regulation of feeding behavior via food intake stimulation with the use of GABA agonists (Kandov et al, 2006; Stratford and Kelley, 1997). Although we have found ZNS to be an agent that is effective in inhibiting and reversing OLZ-associated increases in hyperphagia, body weight and blood glucose in our models, the need to further elucidate the mechanisms of ZNS associated weight loss, as well as a more complete analysis of the risks and benefits of its use as a co-therapy, need to be addressed in order to validate the viability of ZNS as a putative therapeutic agent.

In addition to central mechanisms, there are several known peripheral regulators of food intake, which may be affected by OLZ administration. OLZ may influence hormones associated with the regulation of insulin and/or glucose (Vestri et al, 2007). The typical clinical path toward diabetes is associated with increased adiposity and subsequent changes in insulin sensitivity; however, the rapid onset of diabetes associated with SGA administration, and the disappearance of hyperglycemia after discontinuation in patients suggests that the development of diabetes in patients on SGAs may be an acute drug-related effect (Rettenbacher et al, 2007). There is evidence that OLZ has direct effects on glucose regulation, possibly leading to hyperinsulinemia, hyperglycemia, and insulin resistance (Baptista et al, 2002; Graham et al, 2005; Melkersson and Hulting, 2001; Seemuller et al, 2005). Of note, recent experiments show that SGAs may impair both the insulinresponsive glucose transport system, as well as lipolysis in adipocytes (Vestri et al, 2007), demonstrating that antipsychotic drugs may differentially affect insulin action and metabolism through direct cellular effects in adipocytes. OLZ has also been associated with acute insulin resistance following a single dose in healthy animals (Houseknecht et al, 2007), emphasizing the need for therapies aimed at managing unwanted metabolic side effects.

To our knowledge, there have been no previous reports of the effect of ZNS on blood glucose alone or in attenuating an acute drug-associated effect; however, studies with acetazolamide (a carbonic anhydrase inhibitor antiepileptic) in rats have shown that the integrity of carbonic anhydrase activity is required in order to allow a normal stimulation of insulin release by glucose (Sener et al, 2007). In addition, topiramate, a novel antiepileptic drug, with some similarities to ZNS, has been shown to attenuate OLZassociated weight gain (Liang et al, 2005; Wilkes et al, $2005 \mathrm{a}, \mathrm{b})$, decrease plasma glucose, and increase in vivo insulin sensitivity in adipocytes and skeletal muscle resulting from increases in adiponectin levels (Gustafson et al, 2003). Here, we have shown that subchronic ZNS treatment attenuates chronic OLZ-induced elevated blood glucose. We have also shown that although acute ZNS administration may slightly lower baseline blood glucose levels, it has no significant effect on acute OLZ-induced elevated blood glucose. Therefore, the full complement of the glucose stabilizing properties of ZNS in OLZ-treated patients may require long-term co-therapy, however, the mechanism remains to be determined.

There are some limitations in the present work. Our studies were acute in nature. A study of longer duration with larger sample sizes would help address if the effects of ZNS co-therapy on OLZ-associated weight gain and elevated blood glucose are only transient or if a long-term effect is preserved. It would also provide some mechanistic insight to measure drug plasma levels, in order to determine whether ZNS or OLZ have altered metabolism or bioavailability as a result of concomitant administration. Although it is not possible to clearly specify that the hypophagic effect of ZNS is not due to toxic effects or stress, the reciprocal effects of ZNS on food intake and feeding efficiency in all likelihood suggest that ZNS is regulating energy balance. Most importantly, the exact mechanism(s) of FGA- and SGA-associated increases in body weight and the putative resultant metabolic liability are still unclear. Since various experimental rodent models have shown that sex, drug administration, diet, dose, and the antipsychotic agents used can dramatically affect the results observed, some caution must be used in regard to any potential therapeutic application in a patient population.

In this series of investigations, the SGA OLZ was shown to induce an activation of the appetite circuitry in the rat brain. In parallel, OLZ was also associated with hyperphagia, weight gain, and an acute elevation in blood glucose. ZNS attenuated both c-Fos activation and increased food intake/weight gain associated with OLZ. ZNS also negated the elevation in blood glucose after repeat administration (but not after a single dose). Antipsychotic drugs and anticonvulsant mood stabilizers are now frequently used in combination with one another in treating both schizophrenia and bipolar disorder. ZNS administration in patients has been shown to be well tolerated, with the majority of adverse events being mild to moderate and generally manageable (Baulac and Leppik, 2007), and available data suggest that the risk of developing renal calculi during ZNS treatment is low (Wroe, 2007). In addition, adjunctive ZNS for weight loss in euthymic 
bipolar disorder patients appeared to be effective and generally physically tolerated (Wang et al, 2007). The fact that ZNS has been found to have mood-stabilizing properties and has rarely been reported in association with psychotic symptoms in treated patients is encouraging (Ettinger and Argoff, 2007). These findings suggest that a combined SGA + ZNS approach in psychosis treatment might reduce the adverse weight gain profile seen in some patients and a validation in a patient population is encouraged and may hold promise for improvement in treatment adherence, and ultimately, provide opportunity for better long-term outcomes in schizophrenia.

\section{ACKNOWLEDGEMENTS}

This work was supported by NIH Grant RR0163, funding from Orexigen Therapeutics Inc., and by Eli Lilly and Co. We thank Mark Benvenga, Sonja Billes, Pablo Enriori, Aaron Eusterbrock, Mark Heiman, Erin Jobst, and Lula Tonelli-Lemos for technical support, and Eli Lilly and Co. who generously supplied olanzapine.

\section{DISCLOSURE/CONFLICT OF INTEREST}

Frank P Bymaster, Kishore M Gadde, Ranga K Krishnan, Anthony A McKinney, Ronald P Landbloom, Gary D Tollefson, and Michael A Cowley are employees of, or consultants to, Orexigen Therapeutics, and hold stock in the company. Nicholas M Wallingford, Puspha Sinnayah, and Michael A Cowley are employees of Oregon Health and Science University. Orexigen Therapeutics is investigating the use of olanzapine and zonisamide as a therapeutic. OHSU and Dr Cowley have a significant financial interest in Orexigen Therapeutics Inc., a company that may have a commercial interest in the results of this research and technology. This potential conflict has been reviewed and managed by the OHSU Conflict of Interest in Research Committee and the Integrity Program Oversight Council.

\section{REFERENCES}

Albaugh VL, Henry CR, Bello NT, Hajnal A, Lynch SL, Halle B et al (2006). Hormonal and metabolic effects of olanzapine and clozapine related to body weight in rodents. Obesity (Silver Spring) 14: 36-51.

Arjona AA, Zhang SX, Adamson B, Wurtman RJ (2004). An animal model of antipsychotic-induced weight gain. Behav Brain Res 152: 121-127.

Baptista T, Kin NM, Beaulieu S, de Baptista EA (2002). Obesity and related metabolic abnormalities during antipsychotic drug administration: mechanisms, management and research perspectives. Pharmacopsychiatry 35: 205-219.

Baulac M, Leppik IE (2007). Efficacy and safety of adjunctive zonisamide therapy for refractory partial seizures. Epilepsy Res 75: 75-83.

Brixner DI, Said Q, Corey-Lisle PK, Tuomari AV, L'Italien GJ, Stockdale W et al (2006). Naturalistic impact of secondgeneration antipsychotics on weight gain. Ann Pharmacother 40: 626-632.

Brown RR, Estoup MW (2005). Comparison of the metabolic effects observed in patients treated with ziprasidone $v s$ olanzapine. Int Clin Psychopharmacol 20: 105-112.
Cluderay JE, Harrison DC, Hervieu GJ (2002). Protein distribution of the orexin-2 receptor in the rat central nervous system. Regul Pept 104: 131-144.

Coccurello R, Caprioli A, Ghirardi O, Conti R, Ciani B, Daniele S et al (2006). Chronic administration of olanzapine induces metabolic and food intake alterations: a mouse model of the atypical antipsychotic-associated adverse effects. Psychopharmacology (Berl) 186: 561-571.

Conley RR, Kelly DL (2005). Second-generation antipsychotics for schizophrenia: a review of clinical pharmacology and medication-associated side effects. Isr J Psychiatry Relat Sci 42: 51-60.

Cooper GD, Harrold JA, Halford JC, Goudie AJ (2007). Chronic clozapine treatment in female rats does not induce weight gain or metabolic abnormalities but enhances adiposity: Implications for animal models of antipsychotic-induced weight gain. Prog Neuropsychopharmacol Biol Psychiatry 32: 428-436.

Cooper GD, Pickavance LC, Wilding JP, Halford JC, Goudie AJ (2005). A parametric analysis of olanzapine-induced weight gain in female rats. Psychopharmacology (Berl) 181: 80-89.

Cope MB, Nagy TR, Fernandez JR, Geary N, Casey DE, Allison DB (2005). Antipsychotic drug-induced weight gain: development of an animal model. Int J Obes (Lond) 29: 607-614.

Cvetkovic V, Brischoux F, Jacquemard C, Fellmann D, Griffond B, Risold PY (2004). Characterization of subpopulations of neurons producing melanin-concentrating hormone in the rat ventral diencephalon. J Neurochem 91: 911-919.

Czapinski P, Blaszczyk B, Czuczwar SJ (2005). Mechanisms of action of antiepileptic drugs. Curr Top Med Chem 5: 3-14.

Ebenbichler CF, Laimer M, Eder U, Mangweth B, Weiss E, Hofer A et al (2003). Olanzapine induces insulin resistance: results from a prospective study. J Clin Psychiatry 64: 1436-1439.

eder-Ischia U, Ebenbichler C, Fleischhacker WW (2005). Olanzapine-induced weight gain and disturbances of lipid and glucose metabolism. Essent Psychopharmacol 6: 112-117.

Elman I, Borsook D, Lukas SE (2006). Food intake and reward mechanisms in patients with schizophrenia: implications for metabolic disturbances and treatment with second-generation antipsychotic agents. Neuropsychopharmacology 31: 2091-2120.

Enriori PJ, Evans AE, Sinnayah P, Jobst EE, Tonelli-Lemos L, Billes SK et al (2007). Diet-induced obesity causes severe but reversible leptin resistance in arcuate melanocortin neurons. Cell Metab 5: 181-194.

Ettinger AB, Argoff CE (2007). Use of antiepileptic drugs for nonepileptic conditions: psychiatric disorders and chronic pain. Neurotherapeutics 4: 75-83.

Fadel J, Bubser M, Deutch AY (2002). Differential activation of orexin neurons by antipsychotic drugs associated with weight gain. J Neurosci 22: 6742-6746.

Fontaine KR, Heo M, Harrigan EP, Shear CL, Lakshminarayanan M, Casey DE et al (2001). Estimating the consequences of antipsychotic induced weight gain on health and mortality rate. Psychiatry Res 101: 277-288.

Gadde KM, Franciscy DM, Wagner II HR, Krishnan KR (2003). Zonisamide for weight loss in obese adults: a randomized controlled trial. JAMA 289: 1820-1825.

Goudie AJ, Cooper GD, Halford JC (2005). Antipsychotic-induced weight gain. Diabetes Obes Metab 7: 478-487.

Goudie AJ, Smith JA, Halford JC (2002). Characterization of olanzapine-induced weight gain in rats. J Psychopharmacol 16: 291-296.

Graham KA, Perkins DO, Edwards LJ, Barrier Jr RC, Lieberman JA, Harp JB (2005). Effect of olanzapine on body composition and energy expenditure in adults with first-episode psychosis. Am J Psychiatry 162: 118-123.

Gustafson B, Jack MM, Cushman SW, Smith U (2003). Adiponectin gene activation by thiazolidinediones requires PPAR gamma 2 , but not C/EBP alpha - evidence for differential regulation of the aP2 and adiponectin genes. Biochem Biophys Res Commun 308: 933-939. 
Harris GC, Aston-Jones G (2006). Arousal and reward: a dichotomy in orexin function. Trends Neurosci 29: 571-577.

Harris GC, Wimmer M, Aston-Jones G (2005). A role for lateral hypothalamic orexin neurons in reward seeking. Nature 437: 556-559.

Henderson DC, Cagliero E, Copeland PM, Borba CP, Evins E, Hayden D et al (2005). Glucose metabolism in patients with schizophrenia treated with atypical antipsychotic agents: a frequently sampled intravenous glucose tolerance test and minimal model analysis. Arch Gen Psychiatry 62: 19-28.

Hervieu GJ, Cluderay JE, Harrison DC, Roberts JC, Leslie RA (2001). Gene expression and protein distribution of the orexin-1 receptor in the rat brain and spinal cord. Neuroscience 103: 777-797.

Houseknecht KL, Robertson AS, Zavadoski W, Gibbs EM, Johnson DE, Rollema H (2007). Acute effects of atypical antipsychotics on whole-body insulin resistance in rats: implications for adverse metabolic effects. Neuropsychopharmacology 32: 289-297.

Ichikawa J, Chung YC, Dai J, Meltzer HY (2005). Valproic acid potentiates both typical and atypical antipsychotic-induced prefrontal cortical dopamine release. Brain Res 1052: 56-62.

Ichikawa J, Meltzer HY (1999). Valproate and carbamazepine increase prefrontal dopamine release by 5 -HT1A receptor activation. Eur J Pharmacol 380: R1-R3.

Kalinichev M, Rourke C, Jones DN (2006). Body weights and plasma prolactin levels in female rats treated subchronically with ziprasidone vs olanzapine. Behav Pharmacol 17: 289-292.

Kalra SP, Kalra PS (2004). Overlapping and interactive pathways regulating appetite and craving. J Addict Dis 23: 5-21.

Kandov Y, Israel Y, Kest A, Dostova I, Verasammy J, Bernal SY et al (2006). GABA receptor subtype antagonists in the nucleus accumbens shell and ventral tegmental area differentially alter feeding responses induced by deprivation, glucoprivation and lipoprivation in rats. Brain Res 1082: 86-97.

Kelley AE, Baldo BA, Pratt WE, Will MJ (2005). Corticostriatalhypothalamic circuitry and food motivation: integration of energy, action and reward. Physiol Behav 86: 773-795.

Kuo DY (2002). Co-administration of dopamine D1 and D2 agonists additively decreases daily food intake, body weight and hypothalamic neuropeptide Y level in rats. J Biomed Sci 9: 126-132.

Liang Y, Chen X, Osborne M, DeCarlo SO, Jetton TL, Demarest K (2005). Topiramate ameliorates hyperglycaemia and improves glucose-stimulated insulin release in ZDF rats and $\mathrm{db} / \mathrm{db}$ mice. Diabetes Obes Metab 7: 360-369.

Lieberman JA, Stroup TS, McEvoy JP, Swartz MS, Rosenheck RA, Perkins DO et al (2005). Effectiveness of antipsychotic drugs in patients with chronic schizophrenia. $N$ Engl J Med 353: 1209-1223.

Maldonado-Irizarry CS, Swanson CJ, Kelley AE (1995). Glutamate receptors in the nucleus accumbens shell control feeding behavior via the lateral hypothalamus. J Neurosci 15: 6779-6788.

McElroy SL, Kotwal R, Guerdjikova AI, Welge JA, Nelson EB, Lake $\mathrm{KA}$ et al (2006). Zonisamide in the treatment of binge eating disorder with obesity: a randomized controlled trial. J Clin Psychiatry 67: 1897-1906.

Melkersson KI, Hulting AL (2001). Insulin and leptin levels in patients with schizophrenia or related psychoses - a comparison between different antipsychotic agents. Psychopharmacology (Berl) 154: 205-212.

Minet-Ringuet J, Even PC, Lacroix M, Tome D, de Beaurepaire R (2006). A model for antipsychotic-induced obesity in the male rat. Psychopharmacology (Berl) 187: 447-454.

Modirrousta M, Mainville L, Jones BE (2005). Orexin and MCH neurons express c-Fos differently after sleep deprivation $v s$ recovery and bear different adrenergic receptors. Eur J Neurosci 21: 2807-2816.
Muoio DM, Newgard CB (2006). Obesity-related derangements in metabolic regulation. Annu Rev Biochem 75: 367-401.

Newcomer JW (2005). Second-generation (atypical) antipsychotics and metabolic effects: a comprehensive literature review. CNS Drugs 19(Suppl 1): 1-93.

Newcomer JW, Nasrallah HA, Loebel AD (2004). The Atypical Antipsychotic Therapy and Metabolic Issues National Survey: practice patterns and knowledge of psychiatrists. J Clin Psychopharmacol 24: S1-S6.

Okada M, Kaneko S, Hirano T, Mizuno K, Kondo T, Otani K et al (1995). Effects of zonisamide on dopaminergic system. Epilepsy Res 22: 193-205.

Preti A (2002). Orexins (hypocretins): their role in appetite and arousal. Curr Opin Investig Drugs 3: 1199-1206.

Raskind MA, Burke BL, Crites NJ, Tapp AM, Rasmussen DD (2007). Olanzapine-induced weight gain and increased visceral adiposity is blocked by melatonin replacement therapy in rats. Neuropsychopharmacology 32: 284-288.

Rettenbacher MA, Hummer M, Hofer A, Baumgartner S, Ebenbichler C, Edlinger $M$ et al (2007). Alterations of glucose metabolism during treatment with clozapine or amisulpride: results from a prospective 16-week study. J Psychopharmacol 21: 400-404.

Ritsner MS, Gibel A (2006). The effectiveness and predictors of response to antipsychotic agents to treat impaired quality of life in schizophrenia: a 12-month naturalistic follow-up study with implications for confounding factors, antidepressants, anxiolytics, and mood stabilizers. Prog Neuropsychopharmacol Biol Psychiatry 30: 1442-1452.

Robertson GS, Fibiger HC (1996). Effects of olanzapine on regional C-Fos expression in rat forebrain. Neuropsychopharmacology 14: $105-110$.

Sakurai T (2003). Orexin: a link between energy homeostasis and adaptive behaviour. Curr Opin Clin Nutr Metab Care 6: 353-360.

Schwartz MW, Porte Jr D (2005). Diabetes, obesity, and the brain. Science 307: 375-379.

Sebens JB, Koch T, Ter Horst GJ, Korf J (1995). Differential Fosprotein induction in rat forebrain regions after acute and longterm haloperidol and clozapine treatment. Eur J Pharmacol 273 175-182.

Seemuller F, Forsthoff A, Dittmann S, Born C, Bernhard B, Severus WE et al (2005). The safety and tolerability of atypical antipsychotics in bipolar disorder. Expert Opin Drug Saf 4: 849-868.

Sener A, Jijakli H, Asl SZ, Courtois P, Yates AP, Meuris S et al (2007). Possible role of carbonic anhydrase in rat pancreatic islets: enzymatic, secretory, metabolic, ionic, and electrical aspects. Am J Physiol Endocrinol Metab 292: E1624-E1630.

Strassnig M, Brar JS, Ganguli R (2003). Body mass index and quality of life in community-dwelling patients with schizophrenia. Schizophr Res 62: 73-76.

Stratford TR, Kelley AE (1997). GABA in the nucleus accumbens shell participates in the central regulation of feeding behavior. J Neurosci 17: 4434-4440.

Swanson LW (1998). Brain Maps: Structure of the Rat Brain, 2nd revised edn. Elsevier Science: BV.

Tandon R (2002). Safety and tolerability: how do newer generation 'atypical' antipsychotics compare? Psychiatr Q 73: 297-311.

Tarricone I, Casoria M, Gozzi BF, Grieco D, Menchetti M, Serretti A et al (2006). Metabolic risk factor profile associated with use of second generation antipsychotics: a cross sectional study in a Community Mental Health Centre. BMC Psychiatry 6: 11.

Terry P, Gilbert DB, Cooper SJ (1995). Dopamine receptor subtype agonists and feeding behavior. Obes Res 3(Suppl 4): 515S-523S.

Tosches WA, Tisdell J (2006). Long-term efficacy and safety of monotherapy and adjunctive therapy with zonisamide. Epilepsy Behav 8: 522-526. 
Vestri HS, Maianu L, Moellering DR, Garvey WT (2007). Atypical antipsychotic drugs directly impair insulin action in adipocytes: effects on glucose transport, lipogenesis, and antilipolysis. Neuropsychopharmacology 32: 765-772.

Wang PW, Yang YS, Chandler RA, Nowakowska C, Alarcon AM, Culver J et al (2007). Adjunctive zonisamide for weight loss in euthymic bipolar disorder patients: a pilot study. J Psychiatr Res; e-pub ahead of print.

Ward HG, Nicklous DM, Aloyo VJ, Simansky KJ (2006). Mu-opioid receptor cellular function in the nucleus accumbens is essential for hedonically driven eating. Eur J Neurosci 23: $1605-1613$.

Wilkes JJ, Nelson E, Osborne M, Demarest KT, Olefsky JM (2005a). Topiramate is an insulin-sensitizing compound in vivo with direct effects on adipocytes in female ZDF rats. Am J Physiol Endocrinol Metab 288: E617-E624.

Wilkes JJ, Nguyen MT, Bandyopadhyay GK, Nelson E, Olefsky JM (2005b). Topiramate treatment causes skeletal muscle insulin sensitization and increased Acrp30 secretion in high-fat-fed male Wistar rats. Am J Physiol Endocrinol Metab 289: E1015E1022.

Will MJ, Franzblau EB, Kelley AE (2003). Nucleus accumbens muopioids regulate intake of a high-fat diet via activation of a distributed brain network. J Neurosci 23: 2882-2888.

Wofford MR, King DS, Harrell TK (2006). Drug-induced metabolic syndrome. J Clin Hypertens (Greenwich) 8: 114-119.

Wroe S (2007). Zonisamide and renal calculi in patients with epilepsy: how big an issue? Curr Med Res Opin 23: 1765-1773.

Supplementary Information accompanies the paper on the Neuropsychopharmacology website (http://www.nature.com/npp) 